\title{
STRUCTURE POWER AIRCRAFT FUSELAGE 5774 TRAINER
}

\author{
Fandi Syafri Pratama \\ Teknik Dirgantara, Institut Teknologi Dirgantara Adisutjipto \\ fandisyafripratama@gmail.com
}

\begin{abstract}
The analysis process using software aims to determine whether an object or material is suitable for use or not before carrying out the manufacturing process. To find out whether the material is strong or not when applied to the aircraft, an analysis is carried out using the ABAQUSCAE 6.14 software. This software will show the stress value that occurs in the sandwich composite structure when it receives the load experienced by the aircraft.
\end{abstract}

Keywords: Mechanical Clinching, Riveting, Composite, Aluminum

\section{Pendahuluan}

Penemuan pesawat terbang merupakan suatu kemajuan teknologi yang sangat luar biasa bagi dunia. Sejak manusia menemukan cara untuk dapat terbang makakemajuan teknologi dirgantara di dunia semakin pesat mulai dari bentuk, ukuran dan pesawat tersebut terus mengalami perkembangan seiring dengan kemajuaqn zaman.Struktur fuslage merupakan bagian badan utama sebuah pesawat di mana awak pesawat, penumpang atau kargo ditempatkan, fuselage juga mempunyai beberapabentuk struktur yaitu monocoque dan semi monocoque.Kekuatan struktur fuselage sangat diperhatikan dalam pembuatan pesawat terbang termasuk pembuatan pesawat UAV, kekuatan stuktur fuselage berubah bila jenis material dan ketebalan material berubah. Pesawat 5774 trainer adalah salah satu contoh dari UAV.Untuk manufaktur dan pengujian kekuatan struktur fuselage pesawat terbang UAV memerlukan ketelitian dan pengetahuan yang cukup untuk mendapatkan pesawatyang kuat dan aman untuk di terbangkan. Unmanned Aerial Vehicle (UAV) atau drone merupakan pesawat yang di dalamnya tidak mengangkut awak pesawat atau pilot dan dikendalikan dari jarak jauh ${ }^{[1][2]}$.Pesawat ini dapat digunakan untuk berbagai kepentingan baik militer maupun sipil, di antaranya yaitu untuk pengintaian daerah musuh, pemetaan wilayah pertanian, perkebunan, misi penyelamataan diaerah bencana, dan masih banyak kegunaan lainnya. UAV memiliki beberapa kelebihan dibandingkan dengan pesawat terbang konvensional, yaitu pada peningkatan kemampuan manuver, biaya pengoperasian dan perawatan yang rendah, mengurangi kemungkinan terlacak oleh radar musuh serta mengurangi kemungkinan kecelakaan pada awak pesawat.Sistem kendali otomatis banyak dipakai pada sistem kendali pesawat UAV, sebab pesawat UAV tidak dikendalikan langsung oleh manusia dari dalam pesawat sehingga resiko kecelakaan terhadap pesawat menjadi lebih besar. Untuk membuat sistem kendali otomatis pesawat UAV dibutuhkan beberapa persyaratan, yaitu sebuah platform yang merupakan kombinasi hardware dan software, dan metode control. Platform harus memenuhi parameter, antara lain pengukuran orientasi pesawat dan penentuan koordinat pesawat. Kemudian metode control harus memiliki respon yang baik terhadap input yang dimasukkan. Salah satu sistem kendali yang sering dipakai pada peluru kendali adalah tracking system, sistem ini dipakai untuk mengejar posisi target, selain itu juga diaplikasikan pada automatic landing system, automatic take-off system [3]. Fuselage adalah kabin atau kokpit, yang berisi kursi untuk penumpangnya dan pengendali pesawat. Fuselage juga bisa terdiri dari ruang kargo dan titik-titik penghubung bagi komponen utama pesawat yang lainnya, beberapa pesawat menggunakan struktur open truss. Fuselage dengan tipe open truss terbentuk dari tabung baja atau aluminium. Kekuatan dan kepadatan didapat dari pengelasan tabung - tabung secara bersama yang membentuk bangun segitiga yang disebut trusses. 
Konstruksi dari Warren Truss membuat bentuk sarang dengan batang -batanglongerons, juga batang diagonal dan vertikal. Untuk mengurangi berat maka pesawat kecil menggunakan tabung aluminium alloy yang di rivet atau disekrup menjadi satu bagian dengan bagian yang berhadapan membentuk kerangka. Setelah teknologi berkembang, perancang pesawat mulai melapisi batang - batang truss untuk membuat pesawat lebih streamline meningkatkan kinerja. Awalnyadengan menggunakan kain fabric, yang dapat membengkokkan logam yang ringan seperti aluminium. Dalam beberapa keadaan, kulit luar dapat mendukung semua atau sebagian dari beban yang ditanggung oleh pesawat. Sebagian besar pesawat modern menggunakan struktur kulit yang diketatkan (stressed) yang dikenal dengan nama konstruksi monocoque atau semi-monocoque. Rancangan monocoque menggunakan kulit (logam) yang diketatkan untuk menanggung semua beban (load), ini adalah struktur yang sangat kuat tapi tidak bisa mentoleransi kerusakan berupa goresan atau penyok (berubah/deformasi). Konstruksi Monocoque yang sebenarnya terdiri dari kulit (logam), former (pembentuk) dan bulkhead (penahan). Fomer dan bulkhead memberi bentuk pada fuselage ${ }^{[4]}$. Karena tidak ada kerangka maka kulit haruslah cukup kuat untuk menjaga kepadatan / kekuatan fuselage. Jadi, masalah yang cukup penting dalam konstruksi monocoque adalah menjaga konstruksi agar cukup kuat sementara berat juga harus diperlihatkan agar tidak melebihi batasan. Karena batasan inilah maka struktur semi- monocoque digunakan dibanyak pesawat masa kini.Sistem semi-monocoque menggunakan sub-struktur dimana kulit pesawat ditempelkan. Sub-struktur ini terdiri dari bulkhead dan/atau former terbuat dari berbagai ukuran dan kerangka, memperkuat kulit pesawat dengan menyerap sebagian dari gaya beban dari fuselage. Bagian utama dari fuselage juga termasuk titik sambungan sayap (wing) dan sebuah firewall. Pada pesawat bermesin tunggal, mesinnya biasanya disambungkan didepan fuselage. Ada pembatas tahan - api di antara begian belakang mesin dengan kokpit atau kabin untuk melindungi penerbang dan penumpangnya dari api akibat kecelakaan.Pembatas inilah yang disebut dengan firewall dan biasanya dibuat dari material tahan panas seperti baja.Komposit merupakan material multifase yang didapatkan dari kombinasi material yang berbeda untuk mendapatkan sifat mekanik yang tidak bisa didapatkan apabila material diaplikasikan secara sendiri. Komponen-komponen penyusunkomposit ini tetap bisa dibedakan secara makro dan memiliki sifat yang sama seperti sebelumnya. Material komposit banyak digunakan karena memiliki kombinasi sifat yang tidak bisa didapatkan apabila menggunakan material konvensional pada umumnya seperti logam, polimer, maupun keramik.Sifat komposit memiliki variasi dan tergantung pada berbagai macam faktor seperti jenis komponen yang akan dipilih, distribusi komponen, dan morfologi komponen. Ada beberapa kelebihan dari material komposit apabila dibandingkan dengan material konvensional antara lain yaitu:

a. Material komposit mampu berperan menjadi bagian terintergrasi, misalnya satu komposit mampu menggantikan peran dari beberapa material logam.

b. Komposit memiliki stiffness-to-density ratio yang baik. Rasionya 1/5 dari baja dan 1/2 dari aluminium.

c. Komposit memiliki strength-to-density ratio yang baik. Dengan kelebihan tersebut pesawat maupun kendaraan bermotor bisa bergerak lebih cepat dengan efisiensi bahan bakar yang lebih baik. Kekuatan spesifiknya sekitar tiga hingga lima kali lebih baik apabila dibandingkan dengan material baja,oleh karena itu komponen pesawat terbang menggunakan material kompositkarena lebih ringan namun tetap kuat.

d. Endurance limit (fatigue strength) dari komposit baik. Untuk paduan aluminium maupun baja endurance limit berada pada 50\% dari nilai static strength, sementara untuk unidirectional carbon/epoxy composite bisa mencapi 90\% dari static strength.

Material komposit banyak diaplikasikan terutama pada dunia industri dan salah satunya adalah industri pesawat terbang. Komponen pesawat terbang harus memiliki strength-to- 
density yang baik, komponen harus ringan tapi kuat, dimana dengan berat yang sama komposit mampu menahan beban yang memiliki nilai lebih tinggi jika dibanding dengan material baja agar pesawat mampu terbang dengan kinerja yang lebihbaik.

Secara garis besar ada 3 macam jenis komposit berdasarpenguat yang digunakannya, yaitu :

a. Komposit Serat (Fibrous Composites) merupakan jenis komposit yang hanya terdiri dari satu laminar atau satu lapis yang menggunakan penguat berupa serat/fiber. Fiber yang digunakan bisa berupa glass fibers, carbon fibers, aramid fiber (poly aramide), dan sebagainya. Fiber ini bisa disusun secara acak maupun dengan orientasi tertentu bahkan bias juga dalam bentukyang lebih kompleks seperti anyaman.

b. Komposit Laminat (Laminated Composites) merupakan jenis komposit yangterdiri dari dua lapis atau lebih yang digabung menjadi satu dan setiap lapisnya memiliki karakteristik sifat sendiri.

c. Komposit partikel (Particulate Composites) merupakan komposit yang menggunakan partikel/serbuk sebagai penguatnya dan terdistribusi secara merata dalam matriknya.

\section{Metode Penelitian}

Metode studi literatur merupakan suatu metode pengambilan data yang dilakukan oleh penulis dari berbagai sumber media cetak maupun mediaelektronik, yang berkaitan dengan penelitian yang sedang dilakukan olehpenulis sebagai sarana dalam penunjang dalam pengerjaan skripsi. Sumber Literatur yang digunakan diantara lain:

a. Buku, pengumpuluan data berasal dari literatur buku yang berkaitandengan proses dan kekuatan komposit.

b. Jurnal, pengambilan parameter kekuatan komposit dengan variasi waktu yang terkait dalam menentukan parameter yang tepat di dapatdari jurnal-jurnal pada penelitian sebelumnya.

c. Internet, Pengumpulan data berasal dari situs yang bermanfaat yangmembantu dalam melakukan penelitian.

EksperimenMetode ini dengan menggunakan eksperimental, yaitu denganmembuat spesimen uji dengan menggunakan komposit sandwich. Sedangkan Data Primer berasal dari Metode Wawancara, yaitu metode mengumpulkan data dan informasi terkait dengan penelitian yang akan dilakukan dengan carabertanya langsung kepada narasumber yang berkompeten dalam bidang material aluminium baik itu dosen, laboran tempat melakukan penelitian dan lain sebagainya. Metode Studi Pustakan, yaitu metode pengumpulan data dengan membaca buku, artikel atau jurnal penelitian yang telah dilakukan sebelumnya.Dan data Sekunder Metode Observasi, yaitu metode mengumpulkan data dengan melakukan pelitian langsung terhadap spesimen uji.

\section{Hasil dan Analisis}

Proses analisis menggunakan software bertujuan untuk mengetahui apakah suatu objek atau material layak untuk digunakan atau tidak sebelum melakukan proses manufaktur. Untuk mengetahui material kuat atau tidaknya ketikadiaplikasikan pada pesawat maka dilakukan analisis menggunakan software ABAQUS CAE 6.14. Software ini akan melihatkan nilai tegangan yang terjadi padastruktur komposit sandwich ketika menerima beban yang dialami oleh pesawat. Adapun contoh nilai tegangan yang terjadi dapat dilihat pada gambar 1 

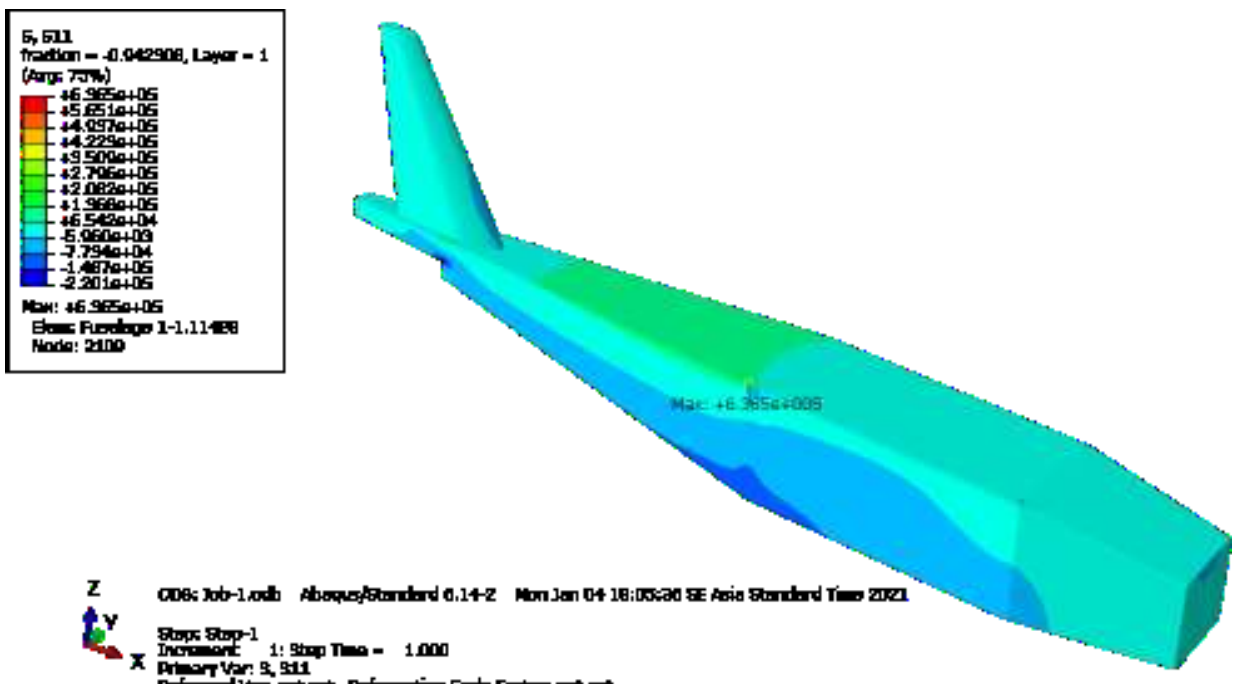

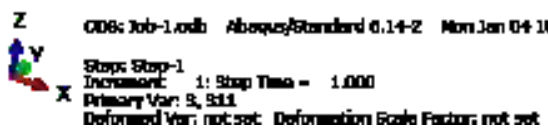

Gambar 1 Nilai Tegangan Arah X Pada layer 1
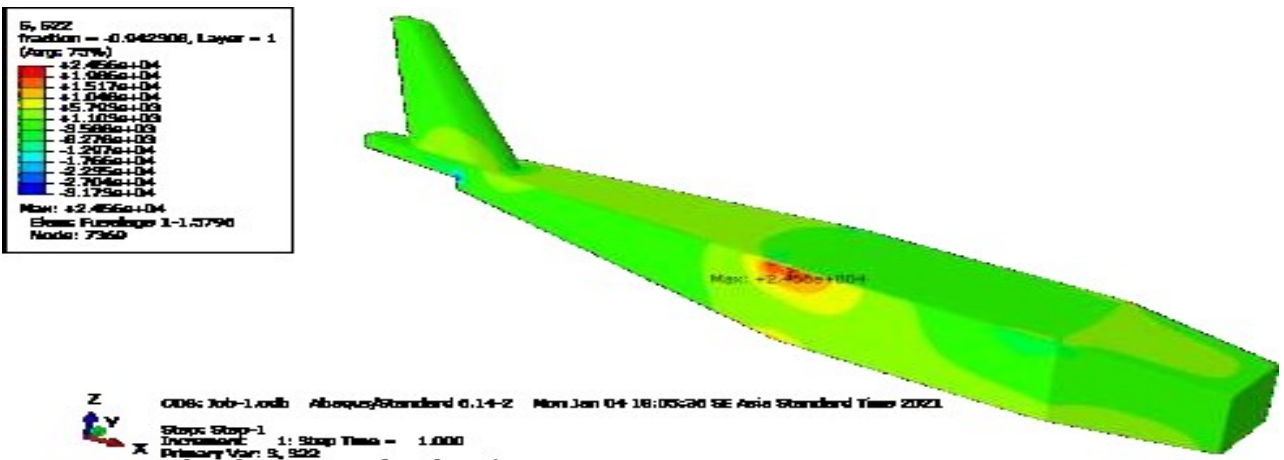

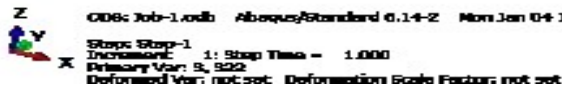

Gambar 2. Nilai Tegangan Arah Y Pada layer 1

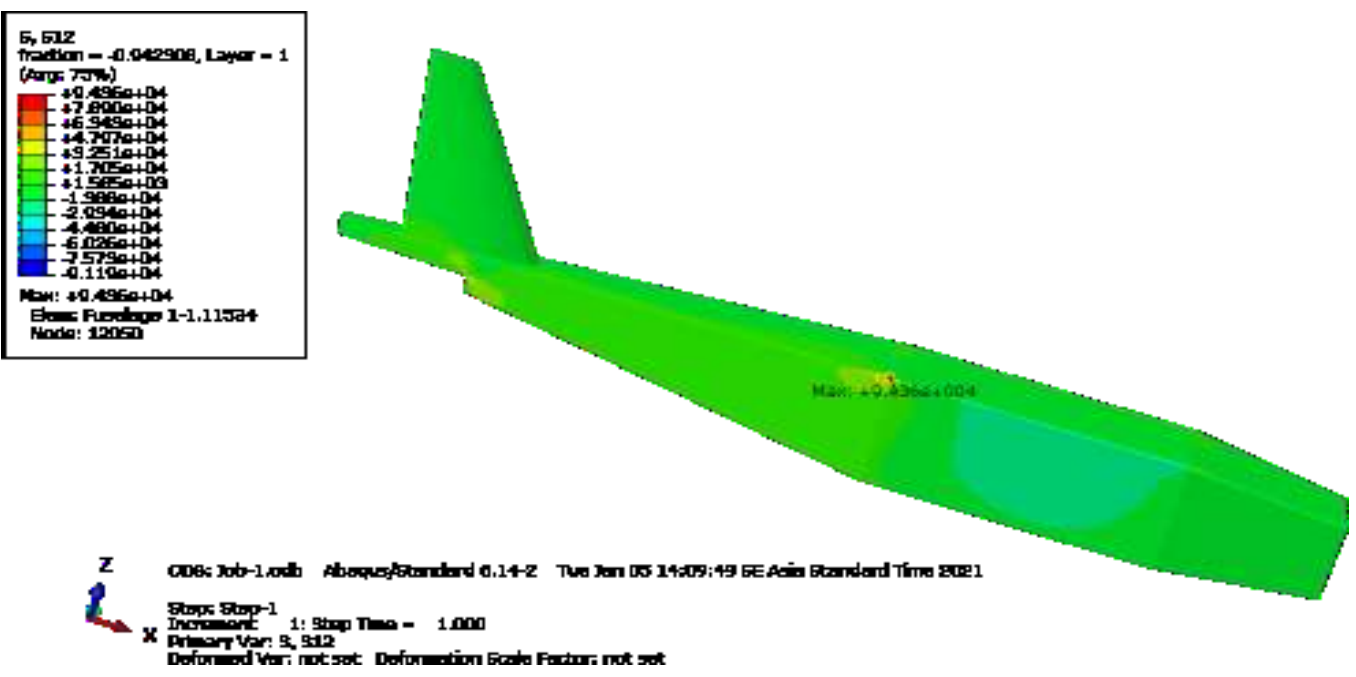

Gambar 3. Nilai Tegangan Geser Pada layer 1 

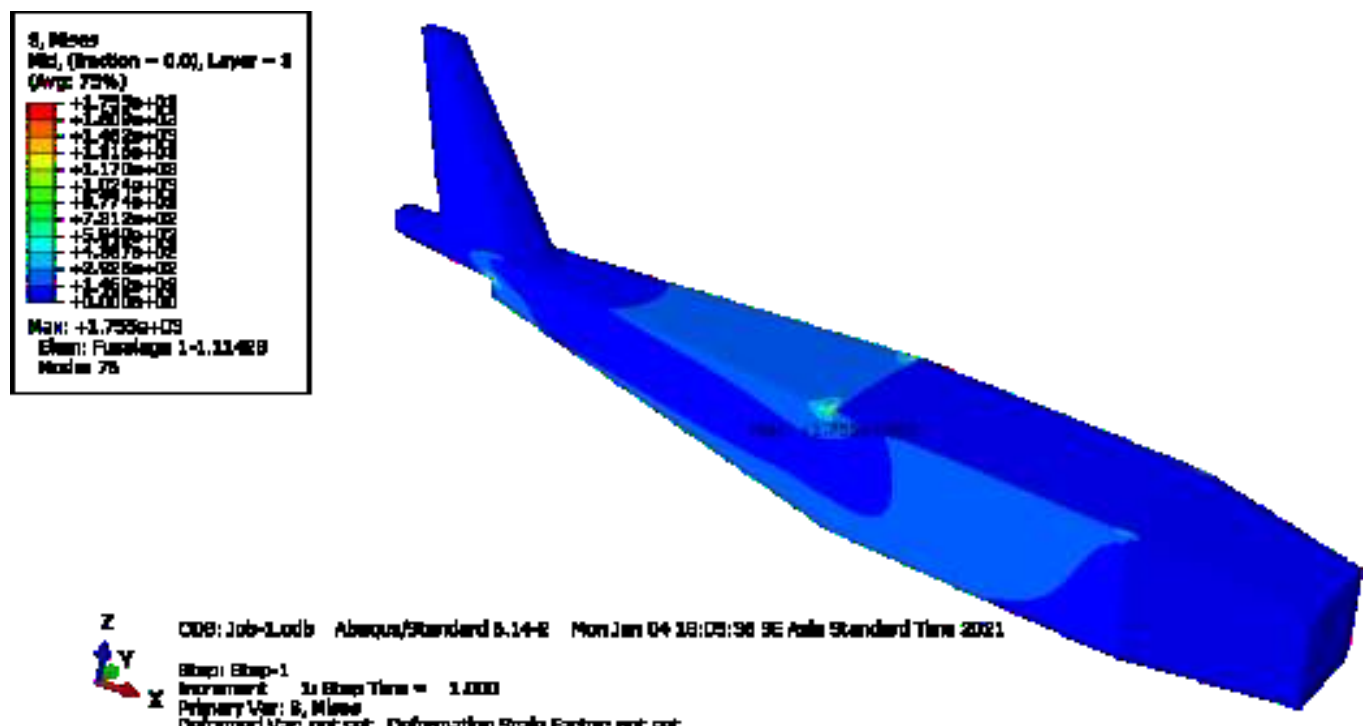

Gambar 4. Nilai Von Misses Pada Core

Tabel 1 Hasil Tegangan Tiap Layer

\begin{tabular}{|l|l|l|c|c|c|l|}
\hline No & Layer & Material & $\boldsymbol{\sigma}_{1}$ & $\boldsymbol{\sigma}_{2}$ & $\boldsymbol{\tau}_{12}$ & Von Mises \\
\hline 1 & Layer 1 & E-Glass & $6,37 \times 10^{5}$ & $2,46 \times 10^{4}$ & $9,44 \times 10^{4}$ & - \\
\hline 2 & Layer 2 & E-Glass & $1,23 \times 10^{5}$ & $1,23 \times 10^{5}$ & $9,11 \times 10^{4}$ & - \\
\hline 3 & Layer 3 & Lantor Soric & - & - & - & $1,76 \times 10^{3}$ \\
\hline 4 & Layer 4 & E-Glass & $7,72 \times 10^{5}$ & $3,30 \times 10^{4}$ & $9,42 \times 10^{4}$ & - \\
\hline 5 & Layer 5 & E-Glass & $1,52 \times 10^{5}$ & $1,56 \times 10^{5}$ & $9,02 \times 10^{4}$ & - \\
\hline
\end{tabular}

Perhitungan failure index (FI) digunakan untuk melihat aman atau tidaknya komposit berdasarkan nilai tegangan yang terjadi. Untuk perhitungan pada lapisanpertama komposit sandwich yaitu sebagai berikut:

Diketahui:

$$
\begin{aligned}
& \sigma_{1}=6,37 \times 10^{5} \mathrm{~N} / \mathrm{m}^{2} \\
& \sigma_{2}=2,46 \times 10^{4} \mathrm{~N} / \mathrm{m}^{2} \\
& r_{12}=9,44 \times 10^{4} \mathrm{~N} / \mathrm{m}^{2} \\
& X=1,28 \times 10^{15} \mathrm{~N} / \mathrm{m}^{2} \\
& Y=6,9 \times 10^{14} \mathrm{~N} / \mathrm{m}^{2} \\
& S=6,9 \times 10^{13} \mathrm{~N} / \mathrm{m}^{2}
\end{aligned}
$$


Perhitungan margin of safety (MS) pada lapisan kedua (core) komposit sandwich yaitu sebagai berikut :

Diketahui:

$$
\begin{aligned}
& \sigma_{\text {all }}=4,00 \times 10^{6} \quad \mathrm{~N} / \mathrm{m}^{2} \\
& \sigma_{\text {app }}=1,76 \times 10^{3} \quad \mathrm{~N} / \mathrm{m}^{2}
\end{aligned}
$$

Tabel 2. Hasil Perhitungan Failure Index dan Margin of Safety

\begin{tabular}{|l|l|l|l|l|l|}
\hline No & Layer & Material & Tsai-Hill & $\begin{array}{l}\text { Margin of } \\
\text { Safety }\end{array}$ & Keterangan \\
\hline 1 & Layer 1 & E-Glass & $3,56 \times 10^{-11}$ & - & Aman \\
\hline 2 & Layer 2 & E-Glass & $1,79 \times 10^{-10}$ & - & Aman \\
\hline 3 & Layer 3 & Lantor Soric & - & $1,52 \times 10^{3}$ & Aman \\
\hline 4 & Layer 4 & E-Glass & $4,78 \times 10^{-11}$ & - & Aman \\
\hline 5 & Layer 5 & E-Glass & $2,26 \times 10^{-10}$ & - & Aman \\
\hline
\end{tabular}

Tabel 3 Hasil Pengujian Tarik

\begin{tabular}{|c|c|c|c|c|c|c|c|c|c|c|}
\hline \multirow{2}{*}{ Spesimen } & \multicolumn{2}{|c|}{ Max Load } & Area & \multicolumn{2}{|c|}{ Elastic Modulus } & \multicolumn{2}{|c|}{ Yield Strengh } & \multicolumn{2}{|c|}{ Yield Point } & $\begin{array}{c}\text { Tegangan } \\
\text { Tarik }\end{array}$ \\
\cline { 2 - 11 } & $\mathbf{k g f}$ & $\mathbf{N}$ & $\mathbf{m m}^{\mathbf{2}}$ & $\mathbf{k g f} / \mathbf{m m}^{2}$ & $\mathbf{M p a}$ & $\mathbf{k g f} / \mathbf{m m}^{2}$ & $\mathbf{M p a}$ & $\mathbf{k g f} / \mathbf{m m}^{2}$ & $\mathbf{M p a}$ & $\mathbf{M p a}$ \\
\hline$D 1$ & 648,779 & 6362 & 62,5 & 128,166 & $1,256 \times 103$ & 8,845 & 86,739 & 8,685 & 85,17 & $1,018 \times 10^{2}$ \\
\hline$D 2$ & 655,745 & 6431 & 62,5 & 131,424 & $1,288 \times 103$ & 9,434 & 92,516 & 8,651 & 84,837 & $1,029 \times 10^{2}$ \\
\hline$D 3$ & 617,445 & 6055 & 62,5 & 97,01 & $9,51 \times 102$ & 8,217 & 80,581 & 8,294 & 81,336 & $9,688 \times 10^{1}$ \\
\hline & & & & & & & & & & \\
\hline Rata-rata & & & & & & & & & & $1,005 \times 10^{2}$ \\
\hline
\end{tabular}

Dari hasil pengujian tarik yang dilakukan di laboratorium bahan Fakultas Teknik Universitas Gajah Mada didapatkan hasil berupa Flexural Strength dan Flexural Mosulus. Adapun data hasil pengujian tarik komposit sandwich untuk semua spesimen uji dapat dilihat pada tabel 4 .

Tabel 4. Hasil Pengujian Bending

\begin{tabular}{|c|c|c|c|c|}
\hline $\begin{array}{c}\text { Kode } \\
\text { Spesimen }\end{array}$ & $\begin{array}{c}\text { Lebar } \\
(\mathbf{m m})\end{array}$ & $\begin{array}{c}\text { Tebal } \\
(\mathbf{m m})\end{array}$ & $\begin{array}{c}\text { Flexural } \\
\text { Strength } \\
\text { (Mpa) }\end{array}$ & $\begin{array}{c}\text { Flexural } \\
\text { Modulus } \\
\text { (Gpa) }\end{array}$ \\
\hline 1 & 15 & 5 & 36,72 & 4,08 \\
\hline 2 & 15 & 5 & 18,24 & 2,104 \\
\hline 3 & 15 & 5 & 9 & 1,928 \\
\hline Rata-rata & & & 21,32 & 2,704 \\
\hline
\end{tabular}




\section{Kesimpulan}

Struktur fuselage pesawat UAV 5774 Trainer menggunakan composite sandwich tersusun atas 3 lapisan dengan fiberglass sebagai skin dan lantorsoric sebagai core. Dari pengujian yang

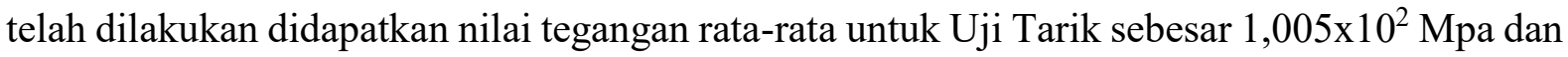
Flexural Strength untuak uji bending sebesar 21,32 Mpa. Dari hasil pengujian dan perhitungan yang telah dilakukan didapatan lah nilai failure criteria tertinggi sebesar $2,26 \times 10^{-10}$ dan yang

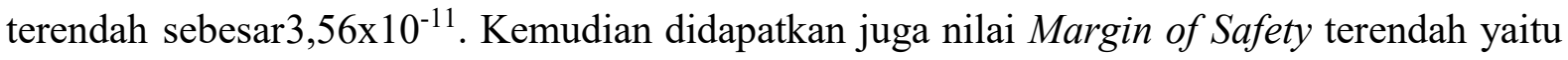
sebesar $1,52 \times 10^{3}$. Hasil tersebut menyatakan bahwa struktur composite sandwich aman dalam menerima beban yang dialami pesawat.

\section{DAFTAR PUSTAKA}

[1] AgusWahyudi Irianto, 2016, Analisis Kekuatan Poros Komposit Polyster Serat Batang Pisang Yang Disusun Simetri 20.40,60 Terhadap Pengujian Punter, Universitas Muhammadiyah Surakarta, Surakarta.

[2] Aria prasetyo,2015, Analisis Sifat Mekanis Komposit vinyl Ester E-Glass WR 185 Menggunakan Metode Hand Lay UP Dan Vacum Resin Infussion Untuk Mengetahui Mekanikal Propertis Dilakukan Pengujian Tarik Dan Tekan, STTA, Yogyakarta.

[3] Burhanudin Rohani, 2016, Proses Produksi Prototipe Pesawat Platform Unmanned Aerial Vehlcle (UAV) Sky King, STTA, Yogyakarta.

[4] Surya Adhy Kusuma, 2016, Perancangan Awal Pesawat UAV Sky King, STTA, Yogyakarta. 